Check for updates

Cite this: RSC Adv., 2017, 7, 55839

\title{
Tetraphenylethylene- and fluorene-functionalized near-infrared aza-BODIPY dyes for living cell imaging $\dagger$
}

\begin{abstract}
Li Zhu, ${ }^{a}$ Wensheng Xie, ${ }^{b}$ Lingyun Zhao, ${ }^{b}$ Yongjie Zhang ${ }^{a}$ and Zhijian Chen (D) *a
Four near-infrared (NIR) boron-azadipyrromethene (aza-BODIPY) dyes 5a- $d$ bearing tetraphenylethyleneand fluorenyl substituents at the 1,7-position or 3,5-position were synthesized and characterized by ${ }^{1} \mathrm{H}$ NMR, ${ }^{13} \mathrm{C} \mathrm{NMR}$ and HRMS. The single crystal structure of compound $5 \mathrm{c}$ was studied by $\mathrm{X}$-ray crystallography. UV/vis and fluorescence spectroscopic studies of the aza-BODIPY dyes 5a-d indicated that the absorption and emission maxima of these dyes were bathochromically shifted up to $48 \mathrm{~nm}$ in comparison with that of the 1,3,5,7-tetraphenyl aza-BODIPY. Moreover, fluorescence quantum yields up to 0.45 were observed for the new dyes. The redox properties of these dyes were investigated by cyclic voltammetry. The observed optical and electrochemical properties of these dyes were further elucidated by the DFT calculation of the frontier molecular orbitals. Owing to their outstanding fluorescence properties, these dyes can be applied as fluorescence imaging probes for living cells.
\end{abstract}

Received 30th September 2017 Accepted 4th December 2017

DOI: $10.1039 / \mathrm{c} 7 \mathrm{ra10820f}$

rsc.li/rsc-advances properties are still limited. Recent efforts have been focused on tuning the absorption and emission wavelength of the azaBODIPYs by attaching strong electron-donating groups, ${ }^{\mathbf{1 4}}$ rigidifying the structure, ${ }^{15}$ or extending the conjugation length of the $\pi$-systems. ${ }^{16}$ Such strategy of chemical modifications can provide substantial shift of the absorption and emission maximum of the dyes to longer wavelength.

In the current work, we report the synthesis and characterization of new aza-BODIPYs dyes bearing tetraphenylethylene or fluorenyl substituents attached at 1,7- or 3,5-positions of the aza-BODIPY core. In comparison with the common azaBODIPYs with 1,3,5,7-tetraphenyl substituents, these new azaBODIPY dyes possess more extended $\pi$-conjugated systems. Thus, bathochromic shifts of the absorption and emission wavelength of these dyes with respect to the tetraphenylsubstituted aza-BODIPYs could be expected. In our studies, the optical absorption and emission properties of these new NIR dyes were investigated by spectroscopic methods. Moreover, the application potential of these new dyes as fluorescent probes in living cell imaging was explored.

\section{Results and discussion}

The synthetic route of the new aza-BODIPYs functionalized with fluorene and tetraphenylethylene is shown in Scheme 1. The starting chalcone type compounds $\mathbf{3 a - d}$ were prepared through an aldol/dehydration reaction of corresponding aldehydes and ketones. In order to improve the yields of $\mathbf{3 a - d}$, an extended reaction time over $36 \mathrm{~h}$ was applied for the reactions. The precursors 4a-d for the aza-BODIPYs were obtained by a Michael addition reaction with nitromethane to the chalcones 
<smiles>[R]C=CC([R])=O</smiles>

$\stackrel{(b)}{\longrightarrow}$<smiles>[R]C(=O)CC([R])C[N+](=O)[O-]</smiles>

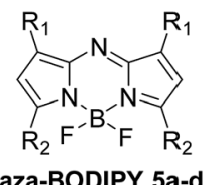

$\mathrm{R}_{1}=$

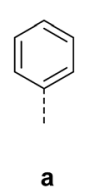

4a-d aza-BODIPY 5a-d a<smiles>c1ccc(C(=C(c2ccccc2)c2ccccc2)c2ccccc2)cc1</smiles>

b
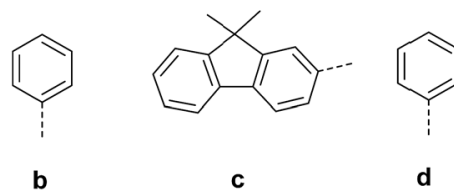

Scheme 1 The synthesis of aza-BODIPYs $5 a-d$. (a) $\mathrm{KOH}$, ethanol, $\mathrm{H}_{2} \mathrm{O}$, rt, $24 \mathrm{~h}$; (b) $\mathrm{CH}_{3} \mathrm{NO}_{2}$, ethanol, diethylamine, $80^{\circ} \mathrm{C}$, reflux, 6-12 h; (c) ammonium acetate, $120^{\circ} \mathrm{C}, 24 \mathrm{~h}$; (d) $\mathrm{BF}_{3} \cdot \mathrm{OEt}_{2}$, DIEA, dry $\mathrm{CH}_{2} \mathrm{Cl}_{2}$, rt, $12 \mathrm{~h}$.

under basic condition. ${ }^{17}$ The compounds $4 a-d$ were then condensed by heating with ammonium acetate under the solventless condition. ${ }^{17,18}$ The crude products of the condensation reaction were treated with $\mathrm{BF}_{3} \cdot \mathrm{OEt}_{2}$ and DIEA ( $N, N$-diisopropylethylamine) in dry $\mathrm{CH}_{2} \mathrm{Cl}_{2}$ at room temperature for $24 \mathrm{~h}$ to give the $\mathrm{BF}_{2}$-chelated dyes $\mathbf{5 a}-\mathbf{d}$. These new dyes were further purified by column chromatography and the chemical structures of all the dyes were characterized by ${ }^{1} \mathrm{H} \mathrm{NMR},{ }^{13} \mathrm{C} \mathrm{NMR}$, as well as high-resolution mass spectroscopy (HRMS).

For further verification of the chemical structure of the new aza-BODIPYs, single crystal growth experiments have been performed for the new dyes (see Experimental section). Finally, single crystal of $\mathbf{5 c}$ suitable for X-ray analysis was obtained and analysed by X-ray diffraction crystallography. Fig. 1 shows the structure of compound $\mathbf{5 c}$ obtained by X-ray crystallography. This dye crystallizes in the monoclinic space group $P 2_{1} / c$ with four molecules in one unit cell. In the crystal structure, an unexpected non-planar boron-dipyrromethene core was observed. The dihedral angles associated with atoms C4-N2C5-C6 and C4-N2-C5-N3 (Fig. 1a) are $168.1^{\circ}$ and $4.2^{\circ}$, respectively. In contrast, the corresponding dihedral angles in the crystal structure of 1,3,5,7-tetraphenyl aza-BODIPY dye ${ }^{19}$ with a planar core are $179.9^{\circ}$ and $0.8^{\circ}$, respectively. Moreover, the boron atom is also not co-planar with the dipyrromethene scaffold, as shown in the side-view of the molecule 5c (Fig. 1b). The dihedral angle associated with atoms N1-B1-N3-C5 is $15.7^{\circ}$ while for 1,3,5,7-tetraphenyl aza-BODIPY this dihedral angle is only $0.7^{\circ} .^{19}$ These results indicate that the borondipyrromethene scaffold of the dye $\mathbf{5 c}$ is highly distorted in the solid state. (a)

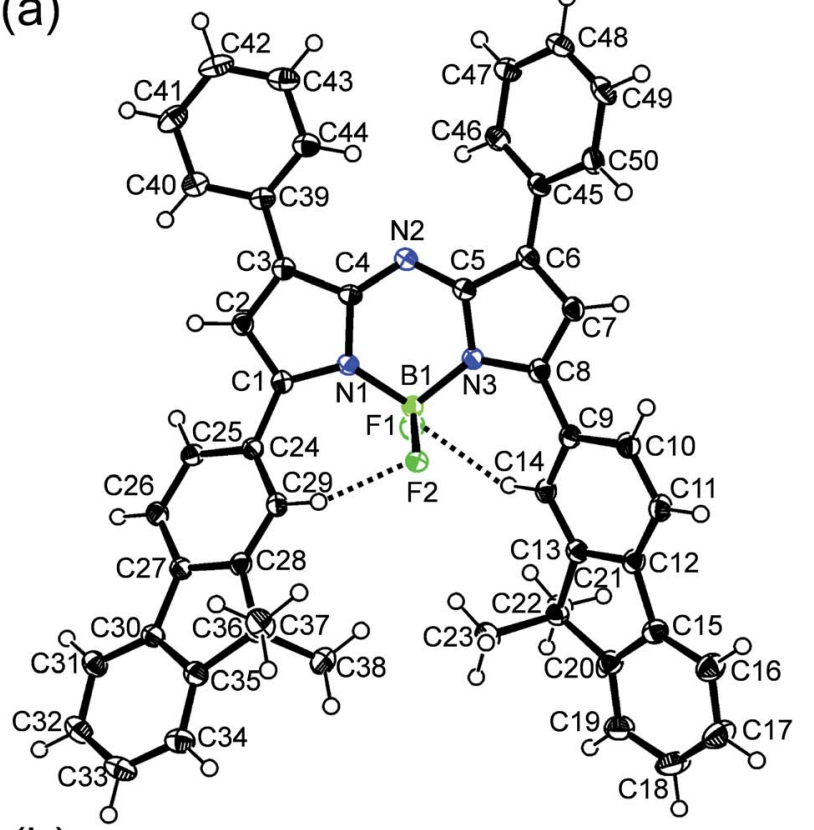

(b)

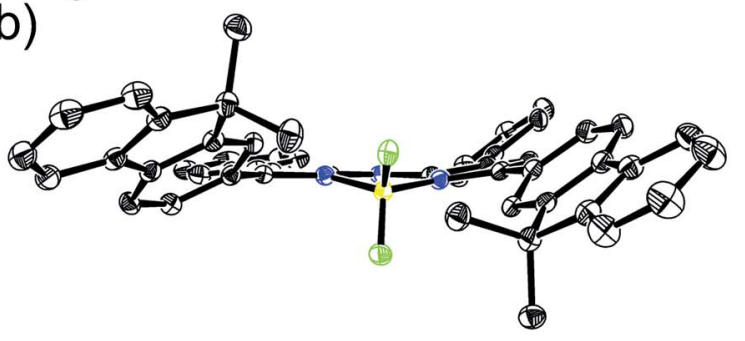

Fig. 1 (a) ORTEP view of Aza-BODIPY 5c. Displacement ellipsoids are drawn at 50\% probability level. (b) Side view along the B1-N2 axis.

In addition, it can be also observed that the two fluorenyls at 3,5-positions in $\mathbf{5 c}$ are not co-planar with the aza-BODIPY core. Nevertheless, the free rotation of the two fluorenyl in $\mathbf{5 c}$ could be hindered by the intramolecular $\mathrm{C}-\mathrm{H} \cdots \mathrm{F}$ hydrogen-bonding interaction between the protons on the two ortho-carbon atoms (C29 and C14) in the 3,5-substituents and the two fluorine atoms, which has been proposed for other aza-BODIPY dyes and BODIPY. ${ }^{20}$ For aza-BODIPY $5 \mathbf{c}$, the C29-H $\cdots$ F1 distance of $2.17 \AA$ and $\mathrm{C} 14-\mathrm{H} \cdots \mathrm{F} 2$ of $2.36 \AA$ were observed in the crystal structure, which are obviously smaller than the sum of van der Waals radii for hydrogen and fluorine atoms $(2.67 \AA),{ }^{21}$ confirming the intramolecular hydrogen-bonding interactions.

The optical properties of the new aza-BODIPYs $5 \mathbf{a}-\mathbf{d}$ in toluene were investigated by UV/vis absorption and fluorescence spectroscopy and the results are summarized in Table 1. All the aza-BODIPY dyes exhibit intense $\mathrm{S}_{0}-\mathrm{S}_{1}$ absorption bands between $600 \mathrm{~nm}$ and $800 \mathrm{~nm}$ (Fig. 2) with molar absorption coefficients comparable with that reported for other azaBODIPYs. Both dyes $\mathbf{5 a}$ and $\mathbf{5 c}$ exhibit an absorption maximum at $708 \mathrm{~nm}$. Meanwhile, absorption maxima at $682 \mathrm{~nm}$ and $677 \mathrm{~nm}$ were observed for the dyes $\mathbf{5 b}$ and $\mathbf{5 d}$, respectively. In comparison with 1,3,5,7-tetraphenyl aza$\operatorname{BODIPY}\left(\lambda_{\mathrm{abs}}=654 \mathrm{~nm}, \lambda_{\mathrm{em}}=684 \mathrm{~nm}\right.$ in toluene) ${ }^{8 a}$ substantial bathochromic shifts up to $c a$. $54 \mathrm{~nm}$ of the absorption bands 
Table 1 Absorption and emission spectroscopic properties of the azaBODIPY dyes $5 a-d$

\begin{tabular}{lllllll}
\hline Dye & $\lambda_{\text {abs }}{ }^{a} / \mathrm{nm}$ & $\varepsilon / \mathbf{M}^{-1} \mathrm{~cm}^{-1}$ & $\lambda_{\mathrm{em}}{ }^{b} / \mathrm{nm}$ & Stokes shift $/ \mathrm{nm}$ & $\Phi^{c}$ & $\tau^{d} / \mathrm{ns}$ \\
\hline 5a & 708 & 77500 & 754 & 46 & 0.45 & 4.75 \\
5b & 682 & 77100 & 730 & 48 & 0.15 & 2.47 \\
5c & 708 & 92400 & 742 & 34 & 0.42 & 4.58 \\
5d & 677 & 86700 & 713 & 36 & 0.19 & 2.17
\end{tabular}

${ }^{a}$ In toluene $\left(c=4 \times 10^{-6} \mathrm{M}\right) \cdot{ }^{b}$ In toluene $\left(c=4 \times 10^{-7} \mathrm{M}, \lambda_{\mathrm{ex}}=520\right.$ $\mathrm{nm})$. ${ }^{c}$ Fluorescence quantum yields determined by using zinc phthalocyanine ( $\Phi=0.30$ in $N, N$-dimethylformamide) as standard. ${ }^{d}$ Fluorescence lifetimes.

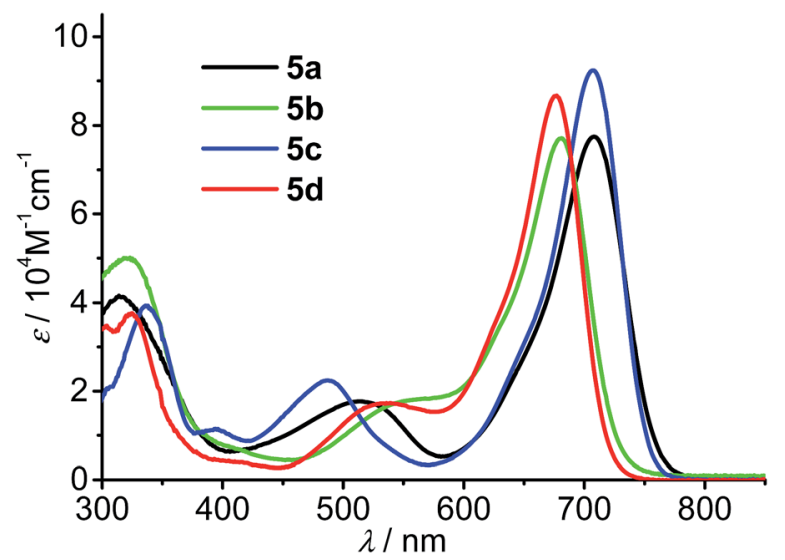

Fig. $2 \mathrm{UV} / \mathrm{vis}$ absorption spectra of the aza-BODIPY dyes $5 a-d$ in toluene.

was obtained for the new aza-BODIPY dyes 5a-d by introducing conjugated fluorene- or tetraphenylethylene-substituents. Moreover, larger bathochromic shifts of the absorption maxima were observed for the dyes $\mathbf{5 a}, \mathbf{5 c}$ bearing the substituents at 3,5-positions than that for the dyes $\mathbf{5 b}, \mathbf{5} \mathbf{d}$ bearing 1,7substituents, implying that the 3,5-substituents have stronger electronic conjugation effect. For all the dyes 5a-d, second absorption bands located between $400 \mathrm{~nm}$ and $550 \mathrm{~nm}$ were observed, which are significantly weaker than the $S_{0}-S_{1}$ bands and could be attributed to the $S_{0}-S_{2}$ transition of these dyes. ${ }^{22}$

The fluorescence spectra (Fig. 3) of all these new azaBODIPYs are approximately the mirror image of their $\mathrm{S}_{0}-\mathrm{S}_{1}$ absorption bands. In toluene, the longest wavelength of the emission maximum (754 nm) was observed for the dye $\mathbf{5 a}$ while emission maxima of 713-742 $\mathrm{nm}$ were observed for dyes $\mathbf{5 b}$-d. It is noteworthy that high fluorescent quantum yields of 0.45 and 0.42 were measured for the dye $\mathbf{5 a}$ and $\mathbf{5 c}$, respectively, which are comparable with that reported for 1,3,5,7tetraphenyl substituted aza-BODIPY $\left(\Phi=0.44\right.$ in toluene).$^{14 d}$ On the other hand, the fluorescent quantum yields of 3,5substituted dyes $\mathbf{5 a}, \mathbf{5 c}$ are much higher than that of 1,7substituted $\mathbf{5 b}, \mathbf{5 d}$, reflecting the effect of the fluorene and tetraphenylethylene substituents at different positions. Meanwhile, the fluorescence lifetimes of the dyes $\mathbf{5 a}$ and $\mathbf{5 c}$ are about the twice of that of $\mathbf{5 b}$ and $\mathbf{5 d}$. These results could be explained by the rigidification of 3,5-fluorenyl and

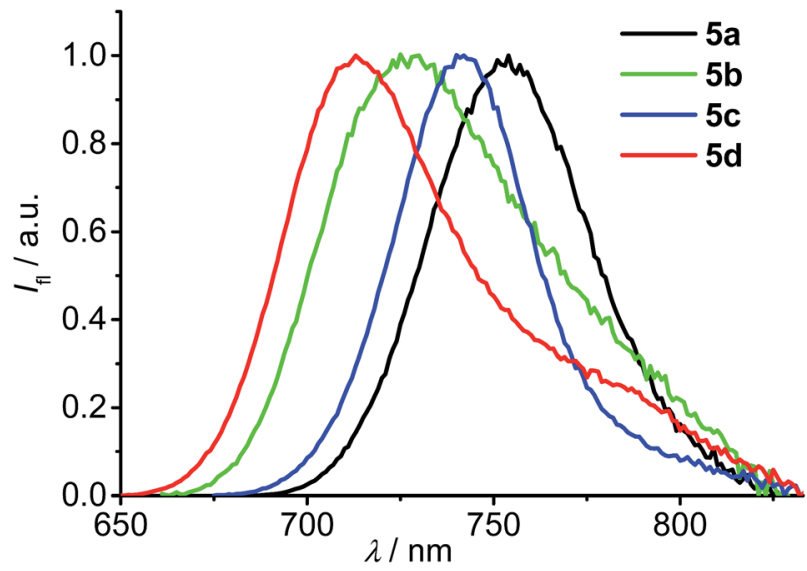

Fig. 3 Fluorescence spectra of the aza-BODIPY dyes 5a-d in toluene.

tetraphenylethylene substituents in $\mathbf{5 a}$ and $\mathbf{5 c}$ due to the $\mathrm{C}-\mathrm{H} \cdots \mathrm{F}$ interactions (vide supra). Such rigidification of the molecular skeleton could be beneficial for the fluorescence since the nonradiative de-excitation pathways through the rotation of the large substituents are restricted.

The electrochemical properties of aza-BODIPYs 5a-d were studied with cyclic voltammetry (CV). According to the resultant CV curves (Fig. S1†), all these dyes exhibit at least one reversible reduction and oxidation wave. As shown in Table 2, the first reduction potentials $\left(v s . \mathrm{Fc} / \mathrm{Fc}^{+}\right.$) of $c a .-0.87 \mathrm{~V}$ and the first oxidation potentials of $0.65-0.78 \mathrm{~V}$ were observed for the dyes 5a-d. In comparison with the 1,3,5,7-tetraphenyl aza-BODIPY $\left(E_{1 / 2}^{\mathrm{ox}}=0.84 \mathrm{~V}, E_{1 / 2}^{\mathrm{red}}=-0.84 \mathrm{~V}\right),{ }^{19}$ the first oxidation potentials of aza-BODIPYs with fluorene- or tetraphenylethylenesubstituents were cathodically shifted about 0.06-0.19 V. Based on the measured oxidation and reduction potentials, the HOMO and LUMO energies of the aza-BODIPYs 5a-d were estimated by applying the widely-used energy level of $\mathrm{Fc} / \mathrm{Fc}^{+}$ $\left(-4.78 \mathrm{eV} v s\right.$. the vacuum level) as reference. ${ }^{23}$ Electrochemical bandgaps between $1.53 \mathrm{eV}$ and $1.65 \mathrm{eV}$ were obtained for dyes 5a-d, which are lower than that for 1,3,5,7-tetraphenyl azaBODIPY. The two 3,5-substituted dyes 5a and 5c exhibit smaller electrochemical bandgaps with respect to that for dyes 5b and 5d. Accordingly, the substitution at 3,5-positions by tetraphenylethylene or fluorenyl groups is more effective in reducing the HOMO-LUMO energy gaps of these dyes than 1,7substitution.

Table 2 Electrochemical properties of aza-BODIPY 5a-d

\begin{tabular}{llllll}
\hline Dye & $E_{1 / 2}^{\mathrm{red} a} / \mathrm{V}$ & $E_{1 / 2}^{\mathrm{ox} a} / \mathrm{V}$ & $\mathrm{HOMO}^{b} / \mathrm{eV}$ & $\mathrm{LUMO}^{b} / \mathrm{eV}$ & $\Delta E_{\mathrm{el}}{ }^{c} / \mathrm{eV}$ \\
\hline $\mathbf{5 a}$ & -0.87 & 0.68 & -5.46 & -3.91 & 1.55 \\
$\mathbf{5 b}$ & -0.87 & 0.78 & -5.56 & -3.91 & 1.65 \\
$\mathbf{5 c}$ & -0.88 & 0.65 & -5.43 & -3.90 & 1.53 \\
$\mathbf{5 d}$ & -0.86 & 0.77 & -5.55 & -3.92 & 1.63
\end{tabular}

${ }^{a}$ First reduction/oxidation potential vs. $\mathrm{Fc} / \mathrm{Fc}^{+} .{ }^{b}$ Calculated from $E_{1 / 2}^{\mathrm{ox}} / E_{1 / 2}^{\mathrm{red}}$ using $-4.78 \mathrm{eV}$ as potential for ferrocene. ${ }^{c} \Delta E_{\mathrm{el}}=$ LUMO - HOMO. 
To gain further insight into the structure-property relationship for the aza-BODIPY dyes 5a-d, DFT calculations were performed at the B3LYP/6-31G (d) level and the resultant frontier molecular orbitals of these dyes were illustrated in Fig. 4. The geometry optimization for these dyes gives a planar structure of the azadipyrrin core. ${ }^{24}$ All the calculated HOMO and LUMO orbitals exhibit $\pi$-conjugated characteristics. The meso-nitrogen in the aza-BODIPY dyes displays essential contribution to all the calculated LUMO orbitals while a node plane is observed at this atom for all the HOMO orbitals. The calculated LUMO levels for $\mathbf{5 a - d}$ are nearly identical while the HOMO levels are varied from -5.05 to $-5.25 \mathrm{eV}$. In addition, the $\pi$-conjugation of the dyes $\mathbf{5 a - d}$ are more extensive as compared with 1,3,5,7-tetraphenyl azaBODIPY. The calculated HOMO-LUMO gaps of $\mathbf{5 a - d}$ are obviously smaller than that for 1,3,5,7-tetraphenyl azaBODIPY. Accordingly, the optical and electrochemical bandgaps of these aza-BODIPY dyes are effectively reduced by incorporating the tetraphenylethylene or fluorenyl moieties into the dye molecules.

The red-NIR emission properties of these new aza-BODIPYs are beneficial for their bioimaging applications. To evaluate the fluorescence imaging performance of the aza-BODIPYs in living cells, MCF-7 cells were incubated with aza-BODIPY dyes 5a-d $\left(500 \mu \mathrm{g} \mathrm{mL}{ }^{-1}\right)$ for $6 \mathrm{~h}$ at $37{ }^{\circ} \mathrm{C}$, respectively. The fluorescence images were shown in Fig. 5. The MCF-7 cells untreated with dyes showed no background fluorescence. However, after incubation with the culture medium contain-

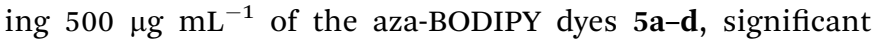
intracellular luminescence was observed. Meanwhile, the overlay of confocal fluorescence images showed that the luminescence was evident in the cytoplasm, not in the nucleus and membrane, which indicated that aza-BODIPY dye 5ad were cell membrane permeable. These observations are in agreement with the results in literatures for other aza-BODIPY imaging probes. ${ }^{11 d, \boldsymbol{e}, \mathbf{1 6 b}}$ Moreover, considering that a long excitation wavelength is essentially important for luminescent imaging of living cells, aza-BODIPY dye 5a-d, which showed intense intracellular near-IR luminescence (Table 1), are promising as fluorescent probes for specific living cell imaging.

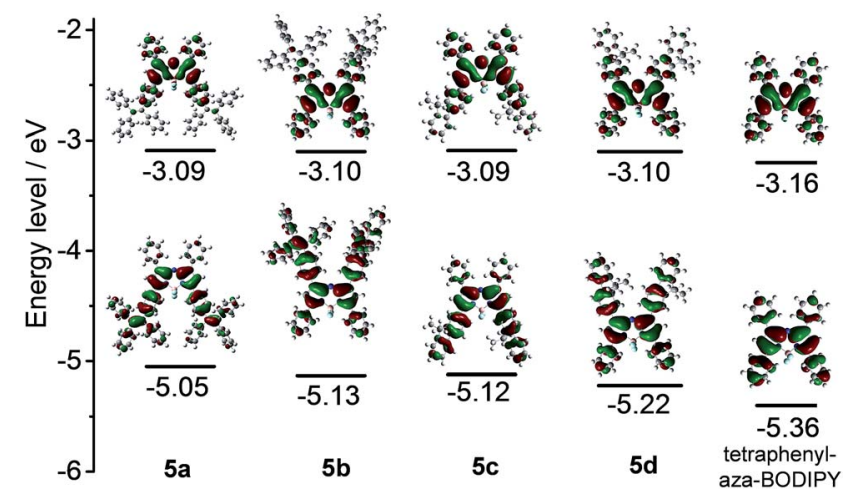

Fig. 4 The calculated HOMOs and LUMOs of dyes $5 a-d$.

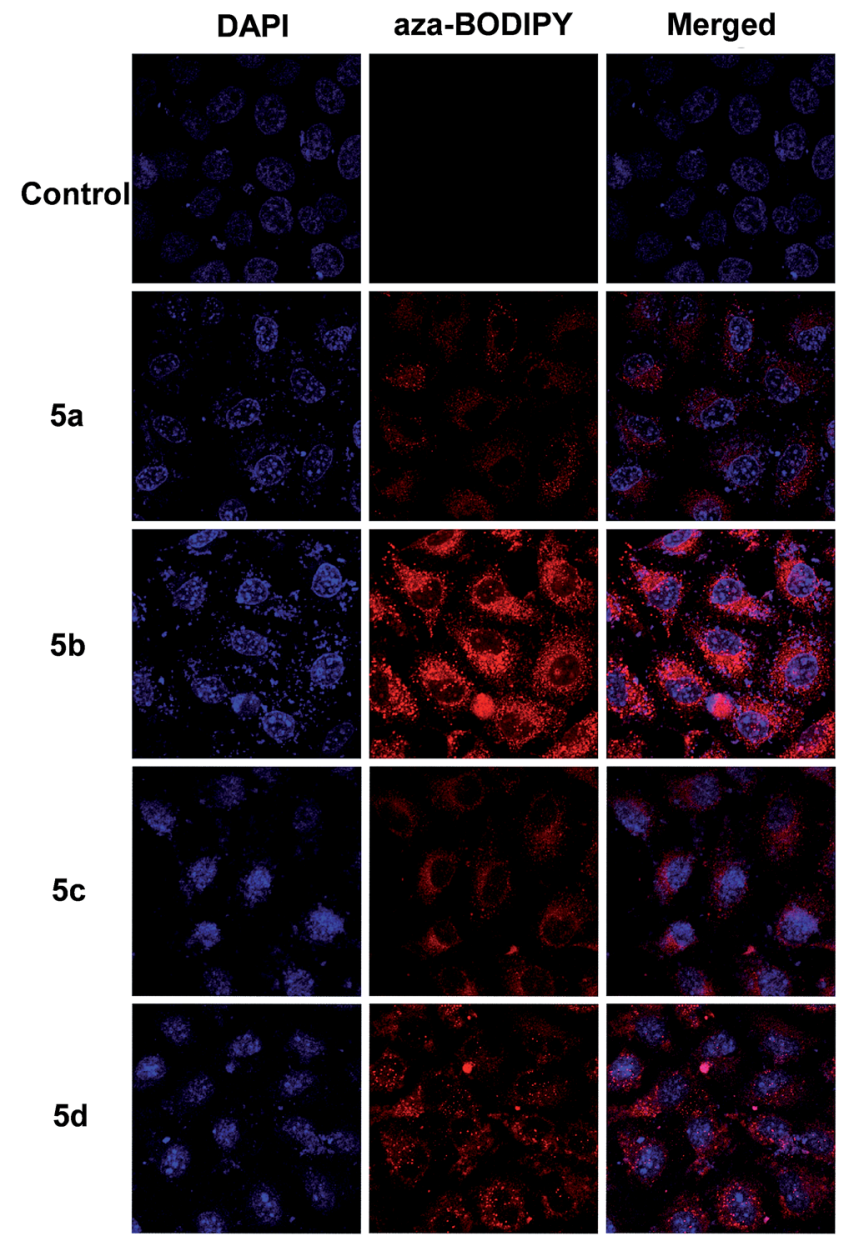

Fig. 5 Fluorescence images of MCF-7 cells after incubation with or without aza-BODIPY $\left(500 \mu \mathrm{g} \mathrm{mL}^{-1}\right)$ for $6 \mathrm{~h}$. Red and blue fluorescence represents aza-BODIPY- and DAPI-stained cell nuclei, respectively.

\section{Conclusions}

In summary, four new NIR fluorescent aza-BODIPY dyes 5ad bearing tetraphenylethylene and 9,9-dimethylfluorenyl moieties at 1,7-position or 3,5-position have been successfully synthesized and characterized. The crystal structure of $5 \mathbf{c}$ revealed an unusual non-planar nature of the core for this dye. In their toluene solution, the absorption and emission bands for the new aza-BODIPY dyes were bathochromically shifted (up to $54 \mathrm{~nm}$ for absorption and $70 \mathrm{~nm}$ for emission) in comparison to the tetraphenylsubstituted analogue. Further electrochemical studies and DFT calculation indicated that the introduction of tetraphenylethylene and fluorenyl units can effectively extend the $\pi$-conjugation length and lower the HOMO-LUMO gaps of these dyes. Based on their red-NIR fluorescence properties, the application prospect of these dyes in living cell imaging was demonstrated.

\section{Experimental section}

\section{Materials and methods}

All starting reagents and materials, unless otherwise specified, were purchased from commercial sources and use without 
further purification. The starting materials 1a-d and 2a-d were synthesized according to the literature. ${ }^{25}{ }^{1} \mathrm{H}$ NMR spectra were recorded on a Bruker AVANCE III at $400 \mathrm{MHz}$ in $\mathrm{CDCl}_{3}$ with tetramethylsilane (TMS) as the internal standard at room temperature and ${ }^{13} \mathrm{C}$ NMR spectra is at $101 \mathrm{MHz}$ with a solvent signal $\left(\mathrm{CDCl}_{3}, 77.16 \mathrm{ppm}\right)$ as a reference. High-resolution mass spectra (HRMS) was performed on a miorOTOF-QII mass spectrometer. UV/vis absorption spectra were recorded on an Agilent Cary 300 UV/vis spectrometer. The steady-state and the time-resolved photoluminescence spectra were measured on an Edinburgh Instruments FLS980 fluorescence spectrometer equipped a NanoLED laser excitation source and a picosecond photon detection module. The fluorescence quantum yields $(\Phi)$ of the dyes were determined by using zinc phthalocyanine $(\Phi=$ 0.30 in $N, N$-dimethylformamide) ${ }^{26}$ as standard. The given quantum yield is the averaged value of data obtained at three different excitation wavelengths. The cyclic voltammetrical measurement was performed with an Ivium potentiostat in a three-electrode single compartment cell using dichloromethane as solvent and tetrabutylammonium hexafluorophosphate as supporting electrolyte (0.1 M).

\section{X-ray crystal structure analysis}

The single crystals of aza-BODIPY 5c were slowly grown from a solution of the dye using mixed solvent (ethanol/ dichloromethane, $3: 1, \mathrm{v} / \mathrm{v}$ ) at ambient conditions over one month. The crystal investigated by XRD (crystal size $0.2 \times 0.18$ $\times 0.12 \mathrm{~mm}$ ) belongs to the monoclinic system with cell parameters of $a=17.671(2) \AA, b=11.6716(11) \AA, c=18.446(2)$ $\AA, \alpha=90^{\circ}, \beta=103.739(2)^{\circ}, \gamma=90^{\circ}$ and $V=3695.7(7) \AA^{3}$. The space group was $P 2_{1} / c$ and $Z=4$. The empirical formula is $\mathrm{C}_{50} \mathrm{H}_{38} \mathrm{BF}_{2} \mathrm{~N}_{3}$ and the molar mass was 729.64. The calculated density was $1.311 \mathrm{~g} \mathrm{~cm}^{-3}$. The three-dimensional X-ray data were collected at $113(2) \mathrm{K}$ with graphite-monochromated Mo $\mathrm{K}_{\alpha}$ radiation $(\lambda=71.073 \mathrm{pm})$ in the range $\theta_{\min }=3.3^{\circ}$ to $\theta_{\max }=$ $27.6^{\circ}$ using $R$-axis rapid IP diffractometer. The intensity data of 46302 independent reflections were collected, and 8498 unique reflections $\left(\left|I^{0}\right|>2 \sigma\left|I^{0}\right|\right)$ were solved by direct methods and refined on $F^{2}$ using the full matrix least-square methods of SHELXL 97. No absorption correction was performed. Hydrogen atoms were calculated and included in the refinement. Nonhydrogen atoms were assigned anisotropic and hydrogen atoms isotropic temperature factors, converging to a final $R$ factor of 0.0375 . The crystal structure data have been deposited with the Cambridge Crystallographic Data Center and allocated the deposition number: CCDC 1547271.

\section{Cell imaging studies}

MCF-7 cells (human breast adenocarcinoma cell line) were originally obtained from the American Type Culture Collection (ATCC) and culture in Dulbecco's Modified Eagle Medium (HDMEM) supplemented with $10 \%$ fetal bovine serum and $1 \%$ of penicillin-streptomycin solution under $37{ }^{\circ} \mathrm{C}$ with $5 \% \mathrm{CO}_{2}$ atmosphere. Briefly, MCF-7 cells were seeded in 48 -well plate with a concentration of $10^{4}$ cells per well and allowed to grow overnight prior to the incubation with culture medium containing $500 \mu \mathrm{g} \mathrm{mL} \mathrm{mL}^{-1}$ aza-BODIPY 5a-d for $6 \mathrm{~h}$, respectively. The cells in control group routinely cultured. All cells were washed three times with phosphate buffered saline and then fixed by $0.5 \mathrm{~mL}$ glutaraldehyde with cell nuclei stained by $4^{\prime}, 6$ diamidino-2-phenylindole (DAPI). Confocal fluorescence imaging of cells was then performed using a Zeiss LSM780 laser scanning confocal microscopy. The fluorescence of aza-BODIPY 5a-d was excited by using a $633 \mathrm{~nm}$ laser.

\section{General procedures for the synthesis of aza-BODIPY 5a-d}

Compounds 4a-d (0.5 g, 0.96-1.36 mmol), and ammonium acetate $(12.9 \mathrm{~g}, 167.2 \mathrm{mmol}$ ) were mixed and heated for $24 \mathrm{~h}$. The reaction mixture was cooled and extracted with $\mathrm{CH}_{2} \mathrm{Cl}_{2}(3 \times$ $50 \mathrm{~mL}$ ). The combined organic phase was dried over anhydrous $\mathrm{MgSO}_{4}$ and the solvent was evaporated under reduced pressure. The residue (crude azadipyrromethene) was dissolved in dry $\mathrm{CH}_{2} \mathrm{Cl}_{2}(60 \mathrm{~mL})$ under $\mathrm{N}_{2}$ atmosphere and DIEA $(0.7 \mathrm{~g}, 5.2$ $\mathrm{mmol}$ ) was added and stirred. After 30 minutes, $\mathrm{BF}_{3} \cdot \mathrm{OEt}_{2}$ (1.025 g, $7.224 \mathrm{mmol}$ ) was added and the mixture was continuously stirred for $24 \mathrm{~h}$ at room temperature. Then the reaction mixture was washed with $\mathrm{NH}_{4} \mathrm{Cl}$ saturated solution $(50 \mathrm{~mL})$, brine $(50 \mathrm{~mL})$ and water $(3 \times 50 \mathrm{~mL})$, and the organic layer was dried over anhydrous $\mathrm{MgSO}_{4}$. After removing the solvents by evaporation, the crude product was purified by silica gel column chromatography ( $n$-hexane/ $\mathrm{CH}_{2} \mathrm{Cl}_{2}=8 / 5$ ) to give the target compounds 5a-d.

1,7-Diphenyl-3,5-bis(4-(1,2,2-triphenylvinyl)phenyl)-borondiuoride-azadipyrromethene (5a). Yield: $71.1 \%$. ${ }^{1} \mathrm{H}$ NMR (400 $\mathrm{MHz}, \mathrm{CDCl}_{3}$, ppm): $\delta=8.03(\mathrm{dd}, J=8.0,1.4 \mathrm{~Hz}, 4 \mathrm{H}), 7.86(\mathrm{~d}, J=$ $8.5 \mathrm{~Hz}, 4 \mathrm{H}), 7.50-7.37$ (m, 6H), 7.16-7.02 (m, 36H); ${ }^{13} \mathrm{C}$ NMR (101 MHz, $\left.\mathrm{CDCl}_{3}, \mathrm{ppm}\right): \delta=158.24,146.66,145.70,143.55$, $143.39,143.34,143.25,142.59,140.30,132.40,131.64,131.55$, 131.35, 129.29, 129.12, 128.56, 127.90, 127.84, 127.66, 126.93, 126.69, 126.65, 119.04; HRMS (ESI): calculated for $\mathrm{C}_{72} \mathrm{H}_{50} \mathrm{BF}_{2} \mathrm{~N}_{3}$, $[\mathrm{M}+\mathrm{Na}]^{+}=1028.3964 \mathrm{~m} / \mathrm{z}$, found $1028.3908 \mathrm{~m} / \mathrm{z}$.

1,7-Bis(4-(1,2,2-triphenylvinyl)phenyl)-3,5-diphenyl-borondiuoride-azadipyrromethene (5b). Yield: $61.1 \%$. ${ }^{1} \mathrm{H}$ NMR (400 $\left.\mathrm{MHz}, \mathrm{CDCl}_{3}, \mathrm{ppm}\right): \delta=8.03-7.95(\mathrm{~m}, 4 \mathrm{H}), 7.77(\mathrm{~d}, J=8.4 \mathrm{~Hz}$, $4 \mathrm{H}), 7.46$ (s, 6H), 7.15-7.04 (m, 30H), $7.00(\mathrm{~d}, J=8.4 \mathrm{~Hz}, 4 \mathrm{H})$, $6.94(\mathrm{~s}, 2 \mathrm{H}) ;{ }^{13} \mathrm{C} \mathrm{NMR}\left(101 \mathrm{MHz}, \mathrm{CDCl}_{3}, \mathrm{ppm}\right): \delta=159.32$, 145.63 , 145.43, 143.58, 143.46, 143.38, 141.92, 140.44, 131.73, $131.47,131.41,131.37,130.74,130.44,129.52,128.53,127.83$, 127.78, 127.73, 126.83, 126.72, 126.67, 118.53; HRMS (ESI): calculated for $\mathrm{C}_{72} \mathrm{H}_{50} \mathrm{BF} 2 \mathrm{~N}_{3},[\mathrm{M}+\mathrm{Na}]^{+}=1028.3964 \mathrm{~m} / \mathrm{z}$, found $1028.3979 \mathrm{~m} / \mathrm{z}$.

1,7-Diphenyl-3,5-bis(9,9-dimethyl-9H-fluoren-2-yl)-borondiuoride-azadipyrromethene (5c). Yield: 75.8\%. ${ }^{1} \mathrm{H}$ NMR (400 $\left.\mathrm{MHz}, \mathrm{CDCl}_{3}, \mathrm{ppm}\right): \delta=8.27(\mathrm{~s}, 2 \mathrm{H}), 8.09(\mathrm{dd}, J=15.7,7.6 \mathrm{~Hz}$, $6 \mathrm{H}), 7.87-7.74(\mathrm{~m}, 4 \mathrm{H}), 7.48(\mathrm{~d}, J=7.8 \mathrm{~Hz}, 8 \mathrm{H}), 7.37$ (d, $J=$ $3.0 \mathrm{~Hz}, 4 \mathrm{H}), 7.17$ (s, 2H), 1.53 (s, 12H); ${ }^{13} \mathrm{C}$ NMR (101 MHz, $\left.\mathrm{CDCl}_{3}, \mathrm{ppm}\right): \delta=159.24,154.75,153.84,145.75,143.47,142.15$, 138.39, 132.50, 130.48, 129.37, 128.63, 128.30, 127.21, 124.27, 122.76, 120.80, 120.72, 120.11, 119.34, 47.13, 27.17; HRMS (ESI): calculated for $\mathrm{C}_{50} \mathrm{H}_{38} \mathrm{BF}_{2} \mathrm{~N}_{3},[\mathrm{M}+\mathrm{Na}]^{+}=752.3025 \mathrm{~m} / \mathrm{z}$, found $752.3029 \mathrm{~m} / \mathrm{z}$. 
1,7-Bis(9,9-dimethyl-9H-fluoren-2-yl)-3,5-diphenyl-borondiuoride-azadipyrromethene (5d). Yield: $60 \% .{ }^{1} \mathrm{H}$ NMR $(400$ $\left.\mathrm{MHz}, \mathrm{CDCl}_{3}, \mathrm{ppm}\right): \delta=8.18(\mathrm{~d}, J=7.9 \mathrm{~Hz}, 2 \mathrm{H}), 8.07$ (d, $J=$ $4.6 \mathrm{~Hz}, 4 \mathrm{H}), 7.99(\mathrm{~s}, 1 \mathrm{H}), 7.80(\mathrm{~s}, 3 \mathrm{H}), 7.49(\mathrm{~s}, 7 \mathrm{H}), 7.38(\mathrm{~s}, 4 \mathrm{H})$, $7.26(\mathrm{~s}, 4 \mathrm{H}), 7.08(\mathrm{~s}, 1 \mathrm{H}), 1.54(\mathrm{~s}, 12 \mathrm{H}) ;{ }^{13} \mathrm{C}$ NMR $(101 \mathrm{MHz}$, $\left.\mathrm{CDCl}_{3}, \mathrm{ppm}\right): \delta=159.20,154.36,154.08,145.83,145.01,140.76$, 138.59, 131.82, 131.75, 130.79, 129.63, 129.11, 128.59, 128.00, 127.24, 123.22, 122.77, 120.49, 53.47, 47.08, 27.25; HRMS (ESI): calculated for $\mathrm{C}_{50} \mathrm{H}_{38} \mathrm{BF}_{2} \mathrm{~N}_{3},[\mathrm{M}+\mathrm{Na}]^{+}=752.3025 \mathrm{~m} / z$, found $752.3029 \mathrm{~m} / \mathrm{z}$.

\section{Conflicts of interest}

There are no conflicts to declare.

\section{Acknowledgements}

We are grateful to the National Natural Science Foundation of China (Grant No. 21676186) and the Tianjin Research Program of Application Foundation and Advanced Technology (Grant No. 15JCZDJC31400) for financial support.

\section{Notes and references}

1 (a) L. Yuan, W. Lin, K. Zheng, L. He and W. Huang, Chem. Soc. Rev., 2013, 42, 622-661; (b) V. Pansare, S. Hejazi, W. Faenza and R. K. Prud'Homme, Chem. Mater., 2012, 24, 812-827.

2 A. Mishra, R. K. Behera, P. K. Behera, B. K. Mishra and G. B. Behera, Chem. Rev., 2000, 100, 1973-2012.

3 C. Jiao, N. Zu, K.-W. Huang, P. Wang and J. Wu, Org. Lett., 2011, 13, 3652-3655.

4 U. Mayerhffer, K. Deing, K. Gruß, H. Braunschweig, K. Meerholz and F. Würthner, Angew. Chem., Int. Ed., 2009, 48, 8776-8779.

5 J. Rodríguez-Hernádez, J. Qu, E. Reuther, H. A. Klok and K. Müllen, Polym. Bull., 2004, 52, 57-64.

6 (a) G. M. Fischer, A. P. Ehlers, A. Zumbusch and E. Daltrozzo, Angew. Chem., Int. Ed., 2007, 46, 3750-3753; (b) S. Shimizu, T. Iino, A. Saeki, S. Seki and N. Kobayashi, Chem.-Eur. J., 2015, 21, 2893-2904.

7 K. Cai, J. Xie and D. Zhao, J. Am. Chem. Soc., 2014, 136, 28-31. 8 (a) A. Loudet and K. Burgess, Chem. Rev., 2007, 107, 48914932; (b) G. Yuan and D. F. O'Shea, Chem. Soc. Rev., 2016, 45, 3846-3864; (c) H. Lu, J. Mack, Y. Yang and Z. Shen, Chem. Soc. Rev., 2014, 43, 4778-4823; (d) Z. Chen, Y. Liu, W. Wagner, V. Stepanenko, X. Ren, S. Ogi and F. Würthner, Angew. Chem., Int. Ed., 2017, 56, 5729-5733.

9 (a) W. Zhao and E. M. Carreira, Chem.-Eur. J., 2006, 12, 72547263; (b) R. Ziessel, G. Ulrich and A. Harriman, New J. Chem., 2007, 31, 496-501; (c) K. Umezawa, Y. Nakamura, H. Makino, A. Daniel Citterio and K. Suzuki, J. Am. Chem. Soc., 2008, 130, 1550-1551; (d) G. Fan, L. Yang and Z. Chen, Front. Chem. Sci. Eng., 2014, 8, 405-417.

10 (a) A. Coskun, M. D. Yilmaz and E. U. Akkaya, Org. Lett., 2007, 9, 607-609; (b) X. D. Jiang, J. Zhang, X. Shao and W. Zhao, Org. Biomol. Chem., 2012, 10, 1966-1968; (c)
L. Zeng, C. Jiao, X. Huang, K. W. Huang, W. S. Chin and J. Wu, Org. Lett., 2011, 13, 6026-6029.

11 (a) X. Zhang, Y. Xiao and X. Qian, Angew. Chem., Int. Ed., 2008, 47, 8025-8029; (b) K. Umezawa, D. Citterio and K. Suzuki, Anal. Sci., 2014, 30, 327-349; (c) G. Fan, Y. X. Lin, L. Yang, F. P. Gao, Y. X. Zhao, Z. Y. Qiao, Q. Zhao, Y. S. Fan, Z. Chen and H. Wang, Chem. Commun., 2015, 51, 12447-12450; (d) W. M. Gallagher, L. T. Allen, C. O'Shea, T. Kenna, M. Hall, A. Gorman, J. Killoran and D. F. O'Shea, Br. J. Cancer, 2005, 92, 1702-1710; (e) S. O. McDonnell, M. J. Hall, L. T. Allen, A. Byrne, W. M. Gallagher and D. F. O'Shea, J. Am. Chem. Soc., 2005, 47, 16360-16361.

12 Y. Yang, Q. Guo, H. Chen, Z. Zhou, Z. Guo and Z. Shen, Chem. Commun., 2013, 49, 3940-3942.

13 J. Min, T. Ameri, R. Gresser, M. Lorenz-Rothe, D. Baran, A. Troeger, V. Sgobba, K. Leo, M. Riede and D. M. Guldi, ACS Appl. Mater. Interfaces, 2013, 5, 5609-5616.

14 (a) D. Wang, R. Liu, C. Chen, S. Wang, J. Chang, C. Wu, H. Zhu and E. R. Waclawik, Dyes Pigm., 2013, 99, 240-249; (b) W. Zheng, B. Wang, C. Li, J. Zhang, C. Wan, J. Huang, J. Liu, Z. Shen and X. You, Angew. Chem., Int. Ed., 2015, 54, 9070-9074; (c) P. Liu, F. Gao, L. Zhou, Y. Chen and Z. Chen, Org. Biomol. Chem., 2017, 15, 1393-1399; (d) L. Jiao, Y. Wu, S. Wang, X. Hu, P. Zhang, C. Yu, K. Cong, Q. Meng, E. Hao and M. G. H. Vicente, J. Org. Chem., 2014, 79, 1830-1835.

15 (a) A. Loudet, R. Bandichhor, K. Burgess, A. Palma, S. O. Mcdonnell, M. J. Hall and D. F. O'Shea, Org. Lett., 2008, 10, 4771-4774; (b) W. Zhao and E. M. Carreira, Angew. Chem., Int. Ed., 2005, 44, 1677-1679.

16 (a) W. Sheng, Y.-Q. Zheng, Q. Wu, Y. Wu, C. Yu, L. Jiao, E. Hao, J.-Y. Wang and J. Pei, Org. Lett., 2017, 19, 28932896; (b) W. Sheng, J. Cui, Z. Ruan, L. Yan, Q. Wu, C. Yu, Y. Wei, E. Hao and L. Jiao, J. Org. Chem., 2017, 82, 1034110349.

17 (a) A. Loudet, R. Bandichhor, L. Wu and K. Burgess, Tetrahedron, 2008, 64, 3642-3654; (b) M. J. Hall, S. O. Mcdonnell, J. Killoran and D. F. O'Shea, J. Org. Chem., 2005, 70, 5571-5578.

18 (a) A. Gorman, J. Killoran, C. O'Shea, T. Kenna, W. M. Gallagher and D. F. O'Shea, J. Am. Chem. Soc., 2004, 126, 10619-10631; (b) M. Grossi, A. Palma, S. O. Mcdonnell, M. J. Hall, D. K. Rai, J. Muldoon and D. F. O'Shea, J. Org. Chem., 2012, 77, 9304-9312.

19 R. Gresser, PhD thesis, Technischen Universität Dresden, 2011.

20 (a) J. Chen, J. Reibenspies, A. Derecskei-Kovacs and K. Burgess, Chem. Commun., 1999, 24, 2501-2502; (b) Q. Bellier, S. Pégaz, C. Aronica, G. B. Le, C. Andraud and O. Maury, Org. Lett., 2011, 13, 22-25.

21 A. Bondi, J. Phys. Chem., 1964, 68, 441-451.

22 X. Ma, X. Mao, S. Zhang, X. Huang, Y. Cheng and C. Zhu, Polym. Chem., 2013, 4, 520-527.

23 P. I. Djurovich, E. I. Mayo, S. R. Forrest and M. E. Thompson, Org. Electron., 2009, 10, 515-520. 
24 J. K. Karlsson and A. Harriman, J. Phys. Chem. A, 2016, 120, 2537-2546.

25 (a) M. O. Wolf, A. H. H. Fox and M. A. Fox, J. Org. Chem., 1996, 61, 287-294; (b) X. Zhang, Z. Chi, H. Li, B. Xu, X. Li, W. Zhou, S. Liu, Y. Zhang and J. Xu, Chem.-Asian J., 2011, 6, 808-811; (c) N. Lardiés, I. Romeo, E. Cerrada, M. Laguna and P. J. Skabara, Dalton Trans., 2007, 251, 5329-5338; (d) M. Y. Yuen, S. C. F. Kui, K. H. Low, C. C. Kwok, S. S. Y. Chui, C. W. Ma, N. Zhu and C. M. Che, Chem.-Eur. J., 2010, 16, 14131-14141.

26 N. Kobayashi, T. Ashida and T. Osa, Chem. Lett., 1992, 21, 2031-2034. 